\title{
Frequency of paradoxical effect with caspofungin in Candida albicans
}

\author{
D. A. Stevens
}

Received: 29 November 2008 / Accepted: 12 December 2008 / Published online: 8 January 2009

(C) Springer-Verlag 2008

To the editor,

In their article regarding the paradoxical growth effect with echinocandins, Fleischhacker et al. [1], discussing their findings with caspofungin, state: "Stevens et al. did not demonstrate [a paradoxical effect, i.e., growth in concentrations above an apparent $\mathrm{MIC}$ ] in a ... group of C. albicans isolates...," citing two of our papers $[2,3]$. However, in our original description of the paradoxical effect with caspofungin [2], we reported the phenomenon in two sets of C. albicans isolates, $16 \%$ of 25 isolates and $18 \%$ of 17 isolates, and in the later paper studying the mechanism [3], we had expanded the study of frequency to 65 isolates, of which $22 \%$ had shown the effect. In our most recently published update [4], we reported the frequency as $17 \%$ of 102 C. albicans isolates studied at that point. We have presently studied 113 isolates, and have found the caspofungin paradoxical effect (as we defined it [2]) in $15 \%$ of C. albicans isolates. Fleischhacker et al. [1] reported it in $14 \%$ of 101 C. albicans isolates studied with caspofungin.

\section{References}

1. Fleischhacker M, Radecke C, Schulz B, Ruhnke M (2008) Paradoxical growth effects of the echinocandins caspofungin and micafungin, but not of anidulafungin, on clinical isolates of Candida albicans and C. dubliniensis. Eur J Clin Microbiol Infect Dis 27:127-131. doi:10.1007/s10096-007-0411-4

2. Stevens DA, Espiritu M, Parmar R (2004) Paradoxical effect of caspofungin: reduced activity against Candida albicans at high drug concentrations. Antimicrob Agents Chemother 48:3407-3411. doi:10.1128/AAC.48.9.3407-3411.2004

3. Stevens DA, White TC, Perlin DS, Selitrennikoff CP (2005) Studies of the paradoxical effect of caspofungin at high drug concentrations. Diagn Microbiol Infect Dis 51:173-178. doi:10.1016/ j.diagmicrobio.2004.10.006

4. van Asbeck EC, Clemons KV, Martinez M, Tong A-J, Stevens DA (2008) Significant differences in drug susceptibility among species in the Candida parapsilosis group. Diagn Microbiol Infect Dis 62:106-109. doi:10.1016/j.diagmicrobio.2008.04.019

D. A. Stevens $(\bowtie)$

Department of Medicine, Santa Clara Valley Medical Center,

751 S. Bascom Av.,

San Jose, CA 95128-2699, USA

e-mail: stevens@stanford.edu 